\title{
Photoredox Reaction of trans-4-Stilbenecarboxylatopentaamminecobalt(III)
}

\author{
Arnd Vogler and Alfred Kern \\ Universität Regensburg, Institut für Chemie, Universität Regensburg
}

Z. Naturforsch. 34b, 271-274 (1979); received November 13, 1978

Redox Reaction, Photochemistry, Cobalt(III) Complex, Stilbenecarboxylate

The irradiation $(\lambda=313 \mathrm{~nm})$ of aqueous $\left[\mathrm{Co}(\mathrm{III})\left(\mathrm{NH}_{3}\right)_{5} \mathrm{TSC}\right]^{2+} \quad\left(\mathrm{TSC}^{-}=\right.$trans -4 stilbenecarboxylate) leads to a redox reaction with formation of $\mathrm{Co}^{2+}$ as has been shown previously. The TSC- ligand is oxidized to the radical in the primary photoreaction. At higher complex concentrations $\left(\sim 10^{-2} \mathrm{M}\right)$ this TSC radical is oxidized to stable products $(\Phi=0.09 \pm 0.02)$ by $\left[\mathrm{Co}\left(\mathrm{NH}_{3}\right)_{5} \mathrm{TSC}\right]^{2+}$, which is reduced to $\mathrm{Co}^{2+}$ leading to release of the TSC- ligand $(\Phi=0.07 \pm 0.02)$. $\mathrm{Co}^{2+}$ is thus formed by both the secondary and the primary photochemical reaction $\left(\Phi_{\text {overall }}=0.16\right)$. At low complex concentrations $\left(<10^{-4} \mathrm{M}\right)$ in the presence of air, the primary TSC radical is scavenged by $\mathrm{O}_{2}$. Benzaldehyde is an oxidation product. This reduces the formation of $\mathrm{Co}^{2+}$ to $\Phi=0.09 \pm 0.02$, which is taken to be the efficiency of the primary photochemical step. It is suggested that the photoredox reaction is initiated by an electron transfer from the first excited singlet of the TSC- ligand. As shown by sensitization experiments, the population of the lowest TSC- triplet leads to the usual trans/cis isomerization of the $\mathrm{TSC}^{-}$ligand, but not to the redox reaction.

\section{Introduction}

Oxidations of organic molecules including olefins and aromatic systems by transition metal ions in thermal reactions have been investigated extensively [1]. In contrast, little is known about photochemical reactions of this type. We explored this possibility and selected for the present study the complex ion $\left[\mathrm{Co}\left(\mathrm{NH}_{3}\right)_{5} \mathrm{TSC}^{2+}\right.$ (TSC- $^{-}=$trans-4stilbenecarboxylate). In this complex, stilbene is linked to $\mathrm{Co}$ (III) via the carboxylic group. $\left[\mathrm{Co}\left(\mathrm{NH}_{3}\right)_{5} \mathrm{TSC}\right]^{2+}$ has already been shown to undergo a photoredox reaction with the formation of $\mathrm{Co}$ (II) [2]. However, no attention has been paid to the site of oxidation.

\section{Experimental}

For the preparation of materials and analytical procedures see ref. [2].

The light source was a high-pressure mercury arc Osram HBO $100 \mathrm{~W} / 2$. An interference filter, Schott UV-PIL 313, was used to isolate the $313 \mathrm{~nm}$ mercury line. The photolyses were carried in 1 and $5 \mathrm{~cm}$ cylindrical spectrophotometer cells. Deaeration was achieved by saturating the solutions with argon. For quantum yield determinations the complex concentrations were adjusted to an optical density of around $\mathrm{A}=2$ at $313 \mathrm{~nm}$ so that complete light absorption occurred. The photolyses were limited to less than $10 \%$ reaction. Absorbed light intensities were determined by ferrioxalate [3] actinometry.

Requests for reprints should be sent to Prof. Dr. A. Vogler, Institut für Chemie der Universität Regensburg, Universitätsstraße, D.8400 Regensburg.

0340-5087/79/0200-027 I/ $\$ 01.00 / 0$
Emission spectra were measured with an Aminco spectrofluorometer. For measurements of visible and ultraviolet absorption spectra, either a Cary 14 or a Varian-Techtron Super Scan 3 spectrophotometer were used. Extinction coefficients at selected wavelengths were measured by means of a Zeiss PMQ II or a Bausch and Lomb Spectronic 710 spectrophotometer.

\section{Results}

The results of the previous investigation of $\left[\mathrm{Co}\left(\mathrm{NH}_{3}\right)_{5} \mathrm{TSC}\right]^{2+}[2]$ were confirmed. Upon irradiation of an acidic $\left(0.01 \mathrm{M} \mathrm{HClO}_{4}\right)$ solution of the complex $\left(10^{-3} \mathrm{M}\right)$ with light at $313 \mathrm{~nm}, \mathrm{Co}^{2+}$ was produced with a quantum yield $\Phi=0.16 \pm 0.02$. Simultaneously, TSC - was released which precipitated as HTSC due to its insolubility in acidic solution. The quantum yield of $\mathrm{TSC}^{-}$release was $\Phi=0.07 \pm 0.02$. Free HCSC $\left(\mathrm{CSC}^{-}=c i s\right.$ - 4 -stilbenecarboxylate) and $\left[\mathrm{Co}\left(\mathrm{NH}_{3}\right)_{5} \mathrm{H}_{2} \mathrm{O}\right]^{3+}$ were not detected. When ethanol was added to the photolyzed solutions, HTSC dissolved. Compared to the unphotolyzed solution, the intraligand absorption band of $\mathrm{TSC}^{-}\left(\lambda_{\max }=319 \mathrm{~nm}, \varepsilon=38000\right)$ [2] decreased at all wavelengths. Since this band of the free ligand does not change upon coordination [2], the decrease indicates the disappearance of TSC- upon irradiation. The disappearance efficiency was $\Phi=0.09 \pm$ 0.02 . The photochemical behavior did not change upon deaeration of the solution.

In acidic, but much more diluted solutions of $\left[\mathrm{Co}\left(\mathrm{NH}_{3}\right)_{5} \mathrm{TSC}\right]^{2+}\left(<10^{-4} \mathrm{M}\right)$, the irradiation, again with light of $313 \mathrm{~nm}$ wavelength, showed a dif- 
ferent behavior. In the presence of air $\mathrm{Co}^{2+}$ was produced with $\Phi=0.09 \pm 0.02$. In addition, $\left[\mathrm{Co}\left(\mathrm{NH}_{3}\right)_{5} \mathrm{H}_{2} \mathrm{O}\right]^{3+}$ was detected. At the low complex concentrations used, however, a quantum yield determination for this aquation product was not possible. As indicated by the absence of any HTSC fluorescence $\left(\lambda_{\max }=400 \mathrm{~nm}\right)$ [2], a photorelease of TSC- did not take place. This was confirmed by the spectral variations which accompanied the photolysis (Fig. 1). When the photolysis was continued to completion the spectral pattern did not change. It follows that free HTSC, which is soluble at very low concentrations, was never formed because it should have undergone the typical trans/cis-isomerization [4] in a secondary photolysis. The spectral changes of this isomerization [5] are different from those observed here. One of the photochemical products was definitely benzaldehyde which was identified by gas chromatography [6]. The formation of benzaldehyde is also indicated by the appearance of a new absorption maximum at $247 \mathrm{~nm}$ during the photolysis (Fig. 1). Benzaldehyde has a band maximum at $247 \mathrm{~nm}(\varepsilon=10800)$. These results indicate that the TSC- ligand was cleaved oxidatively at the olefinic double bond. The disappearance of $\mathrm{TSC}^{-}$

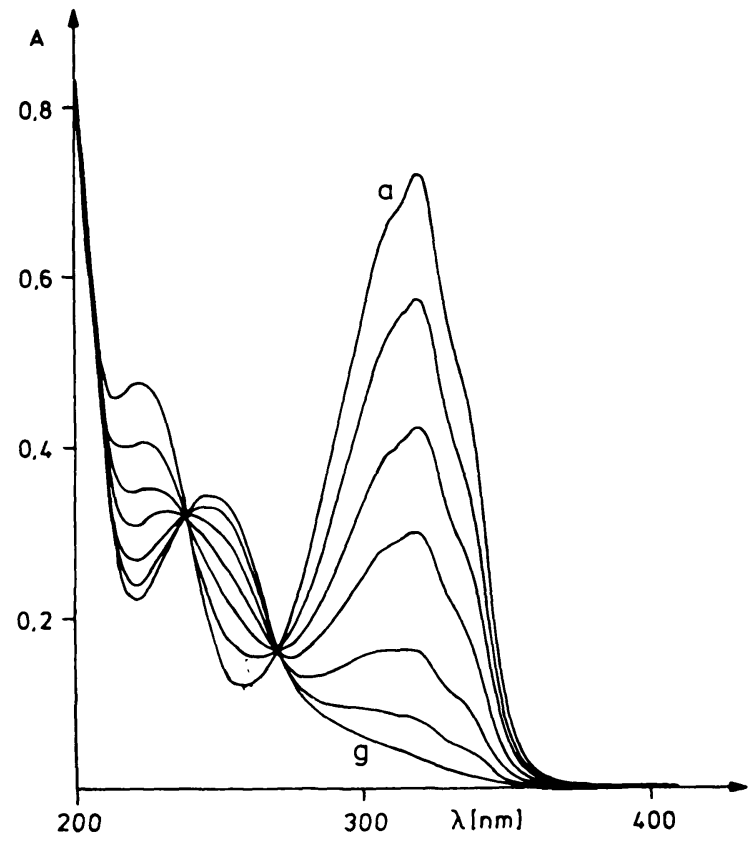

Fig. 1. Spectral changes during the photolysis of aqueous $\left[\mathrm{Co}\left(\mathrm{NH}_{3}\right)_{5} \mathrm{TSC}\right]^{2+}\left(1.92 \cdot 10^{-5} \mathrm{M}\right)$ in a $1 \mathrm{~cm}$ cell, $\lambda_{\text {irr }}=313 \mathrm{~nm}$; (a) initial, (g) $7 \mathrm{~min}$ total irradiation time. was determined by measuring the decrease of extinction at $319 \mathrm{~nm}$, taking into account the residual extinction of the photolysis products $(\varepsilon=2200)$ at this wavelength. At $313 \mathrm{~nm}$, the disappearance quantum yield, which corresponds to the efficiency of TSC- oxidation, $\operatorname{was} \Phi=0.23 \pm 0.02$.

When the photolysis was done in deaerated solutions, again, at low complex concentration $\left(<10^{-4} \mathrm{M}\right)$, the spectral changes differed from those obtained in the presence of air. Isosbestic points as shown in Fig. 1 did not appear. Irradiation led to the formation of free HTSC which was identified by its fluorescence. The irregular changes of the absorption spectrum are attributed to the trans/cisisomerization of released $\mathrm{TSC}^{-}$resulting from secondary photolysis.

In addition to the direct photolysis, sensitization experiments were carried out. Biacetyl and $p$-benzoquinone have been used previously in photosensitized trans/cis-isomerizations of stilbenes [7]. Biacetyl $\left(1.2 \cdot 10^{-1} \mathrm{M}\right)$ dissolved in a deaerated aqueous acidic $\left(0.01 \mathrm{M} \mathrm{HClO}_{4}\right)$ solution containing $\left(2.5 \cdot 10^{-5} \mathrm{M}\right)\left[\mathrm{Co}\left(\mathrm{NH}_{3}\right)_{5} \mathrm{TSC}\right]^{2+}$ was irradiated with light of wavelength $405 \mathrm{~nm}$. The light was observed by biacetyl but not by the TSC-ligand. While the fluorescence of biacetyl $\left(\lambda_{\max }=475 \mathrm{~nm}\right)$ was not affected by the presence of the complex, the phosphorescence $\left(\lambda_{\max }=510 \mathrm{~nm}\right)$ was completely quenched. Simultaneously trans- to cis-photoisomerization of TSC$^{-}$occurred as indicated by the spectral variations similar to those observed during the photolysis of the free ligand [5]. The isomerization took place at the coordinated ligand since the sensitization at higher complex concentrations $\left(\sim 3 \cdot 10^{-4} \mathrm{M}\right)$ was not accompanied by a precipitation of HTSC or HCSC. In addition, the sensitized photolysis did not lead to any formation of $\mathrm{Co}^{2+}$. Essentially the same results were obtained with $p$-benzoquinone as sensitizer. Light of wavelengths longer than $405 \mathrm{~nm}$ was used for excitation of $p$-benoquinone.

\section{Discussion}

The results are consistent with the following mechanism. The first step of the photolysis is assumed to occur according to the equation

$$
\begin{aligned}
& {\left[\mathrm{Co}(\mathrm{III})\left(\mathrm{NH}_{3}\right)_{5} \mathrm{TSC}\right]^{2+} \stackrel{\mathrm{h} v}{\longrightarrow}} \\
& {\left[\mathrm{Co}(\mathrm{II})\left(\mathrm{NH}_{3}\right)_{5}\right]^{2+}+\text { TSC-radical }}
\end{aligned}
$$


Such a one-electron transfer generally takes place as the primary process in photoredox reactions of $\mathrm{Co}$ (III) ammine complexes [8,9]. In addition, it is known that in thermal reactions olefins [10] and aromatic molecules [11] are oxidized to radicals by $\mathrm{Co}$ (III).

Whereas the metallo fragment $\left[\mathrm{Co}\left(\mathrm{NH}_{3}\right)_{5}\right]^{2+}$ generated in the photoreaction (1) falls apart to yield $\mathrm{Co}^{2+}$ and ammonia, the fate of the TSCradical depends on the reaction conditions. At high complex concentrations, the TSC-radical is oxidized by unreacted starting complex in a further oneelectron transfer according to the equation

TSC-radical $+\left[\mathrm{Co}(\mathrm{III})\left(\mathrm{NH}_{3}\right)_{5} \mathrm{TSC}\right]^{2+} \rightarrow$ oxidized TSC $+\left[\mathrm{Co}(\mathrm{II})\left(\mathrm{NH}_{3}\right)_{5} \mathrm{TSC}\right]^{+}$

Aryl olefins are well known to undergo two consecutive one-electron oxidations yielding stable products [12]. The labile intermediate $\left[\mathrm{Co}(\mathrm{II})\left(\mathrm{NH}_{3}\right)_{5} \mathrm{TSC}\right]^{+}$ formed in reaction (2) releases finally the $\mathrm{TSC}^{-}$ ligand according to

$$
\left[\mathrm{Co}(\mathrm{II})\left(\mathrm{NH}_{3}\right)_{5} \mathrm{TSC}\right]^{+} \rightarrow \mathrm{Co}^{2+}+5 \mathrm{NH}_{3}+\mathrm{TSC}^{-}
$$

The secondary reactions (2) and (3) do not only explain the origin of the released TSC- ligand, but also the observation that the disappearance of TSC- leading to stable oxidation products occurs with approximately the same quantum yield $(\Phi=0.09 \pm 0.02)$ as the release of the TSC-ligand $(\Phi=0.07 \pm 0.02)$. This mechanism is also consistent with the result that the observed quantum yield for $\mathrm{Co}^{2+}$ formation is twice as high $(\Phi=0.16 \pm 0.02)$ since $\mathrm{Co}^{2+}$ is produced in the primary photochemical step (1) as well as in the secondary thermal reactions (2) and (3).

However, these data can also be explained by a different mechanism. A disproportionation of the TSC radical would lead to the same results according to the equation

$$
2 \text { TSC-radical } \rightarrow \text { oxidized TSC }+ \text { TSC }^{-}
$$

Since $\mathrm{Co}^{2+}$ would not be produced in the secondary reaction (4), the observed quantum yield for $\mathrm{Co}^{2+}$ production $(\Phi=0.16)$ assuming only processes (1) and (4) are operative, should be equal to the efficiency of the primary photoreaction (1). However, such a mechanism can be ruled out by another observation. At low complex concentrations in the presence of air, $\mathrm{Co}^{2+}$ was produced with $\Phi=0.09 \pm 0.02$. Since under these conditions the secondary reactions (2) and (3) or (4) do not take place (see below), it is concluded that the quantum yield $\Phi=0.09$ represents the real efficiency of the photoreaction (1). At high complex concentrations, the secondary reactions (2) and (3) must then take place to explain the observed increase in the quantum yield for $\mathrm{Co}^{2+}$ formation $(\Phi=0.16)$.

At low complex concentration in the presence of air, any secondary reaction producing free TSCdoes not take place. The TSC-radical formed in the photoreaction (1) is now scavenged by oxygen. This leads to a complete oxidation of the TSC radical. Benzaldehyde has been detected as an oxidation product. Since under these conditions the quantum yield for the disappearance of $\operatorname{TSC}^{-}(\Phi=0.23)$ is much higher than that of $\mathrm{Co}^{2-}$ production $(\Phi \pm 0.09)$, the reaction of the TSC radical with $\mathrm{O}_{2}$ seems to form intermediates, probably some kind of peroxy series, which are able to oxidize coordinated TSC-. This oxidation which apparently leads to the disappearance of coordinated TSC- may explain the formation of $\left[\mathrm{Co}\left(\mathrm{NH}_{3}\right)_{5} \mathrm{H}_{2} \mathrm{O}\right]^{3+}$.

The fluorescence quenching of TSC- which occurs upon coordination shows that the first excited singlet of TSC $^{-}$is involved in the photoredox reaction of $\left[\mathrm{Co}\left(\mathrm{NH}_{3}\right)_{5} \mathrm{TSC}\right]^{2+}$ [2]. In contrast, the lowest triplet of $\mathrm{TSC}^{-}$is apparently not able to initiate this redox reaction. Biacetyl or $p$-benzoquinone, which are known to undergo triplet-triplet energy transfer to stilbenes [7], sensitizes only the typical trans/cis-isomerization of $\mathrm{TSC}^{-}$in $\left[\mathrm{Co}\left(\mathrm{NH}_{3}\right)_{5} \mathrm{TSC}\right]^{2+}$.

Since the redox photolysis of $\left[\mathrm{Co}\left(\mathrm{NH}_{3}\right)_{5} \mathrm{TSC}\right]^{2+}$ is accompanied by fluorescence quenching of the initially excited singlet of the TSC- ligand, it has been suggested previously that the intraligand singlet undergoes an excitation energy transfer to a reactive CT (ligand to metal) state of the complex [2]. Such a CT transition is associated with the removal of an electron from a coordinating group and may appear as CT band in the absorption spectrum. In the case of coordinated carboxylates, $\mathrm{RCOO}^{-}$, the electron should be removed from a carboxylic group. The substituent $R$ does not seem to be involved since the $\mathrm{S}_{0} \rightarrow \mathrm{S}_{1}$ transition of TSC-, which is largely of the $\pi \pi^{*}$-type and hence localized on the stilbene moiety, remains unaltered upon coordination [2]. Evidence for the electronic isolation of $\mathrm{R}$ also comes from the observation that the LF-strength of $\mathrm{RCOO}^{-}$hardly varies with changing $R$. As a consequence, the energy of a CT (carboxylate 
to metal) transition should not be affected by $\mathrm{R}$. The observed first CT band of $\left[\mathrm{Co}\left(\mathrm{NH}_{3}\right)_{5} \mathrm{O}_{2} \mathrm{CR}\right]^{2+}$ complexes lies around $50000 \mathrm{~cm}^{-1}\left(e . g .\left[\mathrm{Co}\left(\mathrm{NH}_{3}\right)_{5}\right.\right.$ acetato $\left.{ }^{2+}\right)$. It seems questionable if such a CT state, even a spectroscopically non-observable, lower lying triplet [2], can be populated from the first excited singlet of TSC-, on energy grounds. From the absorption $\left(31,350 \mathrm{~cm}^{-1}\right)$ and fluorescence maximum $\left(25,000 \mathrm{~cm}^{-1}\right)$, the energy of the first excited $\mathrm{TSC}^{-}$singlet $(\mathrm{O}-\mathrm{O})$ can be estimated to be $28,170 \mathrm{~cm}^{-1}$. However, there is an alternative pathway which requires less energy than that for the population of a CT state of this type.

The excited TSC- ligand may directly transfer an electron to $\mathrm{Co}(\mathrm{III})$. Such a process resembles the situation encounterd in intermolecular excited state electron transfer reactions [13]. If $R$ of the carboxylate $\mathrm{R}-\mathrm{COO}^{-}$has an extended $\pi$-electron system such as the stilbene unit of TSC-, the removal of a $\pi$-electron requires much lower potentials compared to the oxidation of aliphatic carboxylates as e.g. acetate. This is illustrated by the lower value of $\mathrm{E}_{1 / 2}=+1.51 \mathrm{~V}$ (vs. SCE) for the oxidation of transstilbene compared to a potential of greater than $+2.0 \mathrm{~V}$ ( $v s . \mathrm{SCE}$ ) for the oxidation of acetate [14].
Additional support for this assumption comes from the observation, that thermal oxidations of arylcarboxylates by $\mathrm{Co}$ (III) lead initially to the loss of a $\pi$-electron of the aromatic nucleus [15].

Neglecting entropy contributions, the reduction potential of the excited TSC- can be calculated from the redox potential of the ground state couple TSC-/TSC and the excitation energy of TSC- $[13]$. This gives a reduction potential of $-1.98 \mathrm{~V}$ for TSCin its first excited singlet using the energy of $S_{1}$ $\left(28,170 \mathrm{~cm}^{-1}\right)$ and $\mathrm{E}_{1 / 2}=+1.51 \mathrm{~V}$ for the oxidation of stilbene (making the assumption that $\mathrm{E}_{1 / 2}$ of TSC- is similar to that of stilbene). In contrast to the first excited singlet, the reduction potential of the lowest triplet if TSC $^{-}$is apparently not sufficient to cause the reduction of $\mathrm{Co}$ (III) as the results of the sensitized photolysis of $\left[\mathrm{Co}\left(\mathrm{NH}_{3}\right) \mathrm{TSC}\right]^{2+}$ show. With the assumption that the energy separation between $S_{1}$ and $T_{1}$ of stilbene $\left(\Delta \mathrm{E}=13,650 \mathrm{~cm}^{-1}\right)$ [4] is the same for TSC-, the reduction potential of the TSC- triplet is now only $-0.30 \mathrm{~V}$.

Financial support for this research by the Deutsche Forschungsgemeinschaft and the Fonds der Chemischen Industrie is gratefully acknowledged.
[1] D. Benson, Mechanisms of Oxidation by Metal Ions, Elsevier, Oxford 1976.

[2] A. W. Adamson, A. Vogler, and I. Lantzke, J. Phys. Chem. 73, 4183 (1969).

[3] C. G. Hatchard and C. A. Parker, Proc. Roy. Soc. Ser. A 235, 518 (1956).

[4] J. Saltiel, J. D'Agostino, E. D. Megarity, L. Metts, K. R. Neuberger, M. Wrighton, and O. C. Zafiriou, Org. Photochem. 3, 1 (1973).

[5] A. Vogler and A. Kern, submitted for publication.

[6] Measurements bei E. Eibler, Universität Regensburg.

[7] G. S. Hammond, J. Saltiel, A. A. Lamola, N. J. Turro, J. S. Bradshaw, D. O. Lowan, R. C. Counsell, V. Vogt, and C. Dalton, J. Am. Chem. Soc. 86, 3197 (1964).

[8] J. F. Endicott, in A. W. Adamson and P. D.
Fleischauer (eds.): Concepts of Inorganic Photochemistry, chapter 3, Wiley, New York 1975.

[9] V. Balzani and V. Carassiti, Photochemistry of Coordination Compounds, Academic Press, New York 1970.

[10] R. M. Dessau, J. Am. Chem. Soc. 92, 6356 (1970).

[11] R. M. Dessau, S. Shih, and E. I. Heiba, J. Am. Chem. Soc. 92, $412(1970)$.

[12] S. D. Ross, M. Finkelstein, and E. J. Rudd, Anodic Oxidation, Organic Chemistry 32, chap. ter 5, Academic Press, New York 1975.

[13] V. Balzani, F. Bolletta, M. T. Gandolfi, and M. Maestri, Topics in Current Chemistry 75, 1 (1978).

[14] L. Eberson and K. Nyberg, J. Am. Chem. Soc. 88, 1686 (1966).

[15] R. M. Dessau and E. I. Heiba, J. Org. Chem. 40, 3647 (1975). 